Original

\title{
Effect of alumina air-abrasion on mechanical bonding between an acrylic resin and casting alloys
}

\author{
Takaya Ishii ${ }^{1)}$, Hiroyasu Koizumi ${ }^{2,3)}$, Naomi Tanoue ${ }^{4)}$, Koji Naito ${ }^{1)}$, \\ Miyuki Yamashita ${ }^{1)}$ and Hideo Matsumura ${ }^{2,3)}$ \\ ${ }^{1)}$ Division of Applied Oral Sciences, Nihon University Graduate School of Dentistry, Tokyo, Japan \\ ${ }^{2}$ Department of Fixed Prosthodontics, Nihon University School of Dentistry, Tokyo, Japan \\ ${ }^{3)}$ Division of Advanced Dental Treatment, Dental Research Center, Nihon University School of Dentistry, \\ Tokyo, Japan \\ ${ }^{4)}$ Nagasaki University Hospital of Medicine and Dentistry, Nagasaki, Japan
}

(Received 24 December 2008 and accepted 15 January 2009)

\begin{abstract}
This study examined the effect of alumina air-abrasion with different pressure on bonding between an acrylic resin and casting alloys. Disk specimens (8 and $10 \mathrm{~mm}$ in diameter) were cast from a silverpalladium-copper-gold (Ag-Pd-Cu-Au, Castwell M.C.12) alloy and a titanium-aluminum-niobium alloy (Ti-6Al-7Nb, T-Alloy Tough). The disks were airabraded with alumina particles $(50-70 \mu \mathrm{m})$ under different air-pressures ( 0 unabraded, 0.1 , and $0.6 \mathrm{MPa}$ ). The disk pairs were bonded together with a tri- $n$ butylborane (TBB)-initiated acrylic resin, and shear bond strengths were determined both before and after thermocycling. Bond strength varied from a maximum of 37.1 MPa to a minimum of 3.6 MPa for the Ag-Pd$\mathrm{Cu}-\mathrm{Au}$ alloy, whereas bond strength to Ti-6Al-7Nb alloy ranged from 34.7 MPa to 0.1 MPa. Specimens abraded with 0.6 MPa pressure recorded the greatest post-thermocycling bond strength (21.7 MPa and 17.9 MPa), and unabraded specimens showed the lowest strength (3.6 MPa and 0.1 MPa) for both alloys. Postthermocycling bond strength to the Ag-Pd-Cu-Au alloy was higher than that to the Ti-6Al-7Nb alloy under identical air-abrading conditions. It can be concluded that alumina air-abrasion with an air-pressure of 0.6
\end{abstract}

Correspondence to Dr. Hiroyasu Koizumi, Department of Fixed Prosthodontics, Nihon University School of Dentistry, 1-8-13 Kanda-Surugadai, Chiyoda-ku, Tokyo 101-8310, Japan

Tel: +81-3-3219-8145

Fax: +81-3-3219-8351

E-mail: koizumi@dent.nihon-u.ac.jp
MPa is effective in enhancing retentive characteristics of the TBB-initiated resin joined to the alloys. ( $\mathrm{J}$ Oral Sci 51, 161-166, 2009)

Keywords: abrasion; Ag-Pd-Cu-Au alloy; alumina; bonding; Ti-6Al-7Nb alloy; resin.

\section{Introduction}

The development of laboratory and adhesive techniques has led to the application of silver-palladium-copper-gold (Ag-Pd-Cu-Au) alloy, titanium-aluminum-niobium (Ti-6Al$7 \mathrm{Nb}$ ) alloy, and other alloys for resin-bonded fixed partial dentures (RBFPDs) (1-6). The bonding between polymeric materials and $\mathrm{Ag}-\mathrm{Pd}-\mathrm{Cu}-\mathrm{Au}$ alloys has improved by use of thiol or thione monomers $(7,8)$, whereas bonding to Ti$6 \mathrm{Al}-7 \mathrm{Nb}$ has improved through the use of primers with phosphate $(9,10)$.

Before the bonding procedure, the priming systems require air-abrasion with alumina to mechanically clean the surfaces and to increase the surface bonding area. It is therefore necessary to determine the appropriate conditions for alumina air-abrasion. Although the effects of alumina abrasion on bond strength have been reported for cobalt-chromium, nickel-chromium, and gold alloys as well as titanium (11-15), only limited information is available about Ag-Pd-Cu-Au and Ti-6Al-7Nb alloys (16). The purpose of the current study was to evaluate the influence of air-abrasion with alumina on mechanical bonding between an acrylic resin and two casting alloys. 
Table 1 Materials assessed

\begin{tabular}{|c|c|c|c|c|}
\hline Material / Trade name & Abbreviation & Manufacturer & Lot number & Composition (mass \%) \\
\hline \multicolumn{5}{|l|}{ Casting alloy } \\
\hline \multirow[t]{2}{*}{ Castwell M.C.12 } & \multirow[t]{2}{*}{$\mathrm{Ag}-\mathrm{Pd}-\mathrm{Cu}-\mathrm{Au}$} & \multirow[t]{2}{*}{ GC Corp. } & 0602021 & \multirow[t]{2}{*}{$46 \mathrm{Ag}, 20 \mathrm{Pd}, 20 \mathrm{Cu}, 12 \mathrm{Au}$} \\
\hline & & & 0707201 & \\
\hline T-Alloy Tough & Ti-6Al-7Nb & GC Corp. & 408041 & $86.5 \mathrm{Ti}, 7 \mathrm{Nb}, 6 \mathrm{Al}$ \\
\hline \multicolumn{5}{|l|}{ Alumina powder } \\
\hline Hi-Aluminas & & Shofu Ine. & & $50-70 \mu \mathrm{m}$ grain sized alumina \\
\hline \multicolumn{5}{|l|}{ Luting material } \\
\hline Methyl methacrylate & MMA & Wako Pure Chemical Ind., Ltd. & ALP5224 & $99.8 \mathrm{MMA}$ \\
\hline Super-Bond Catalyst & & Sun Medical Co., Ltd. & RT13 & TBB \\
\hline Super-Bond Opaque powder & & Sun Medical Co., Ltd. & $\mathrm{SF} 1$ & PolyMMA, Titanium oxide \\
\hline
\end{tabular}

MMA, Methyl methacrylate; TBB, Tri- $n$-butylborane derivative

\section{Materials and Methods}

An Ag-Pd-Cu-Au alloy (Castwell M.C.12, GC Corp., Tokyo, Japan) and Ti-6Al-7Nb alloy (T-Alloy Tough, GC Corp.) designed for cast restorations and partial denture frameworks were selected as the substrate materials. Alumina powder $(50-70 \mu \mathrm{m}$ grain size; Hi-Aluminas, Shofu, Inc., Kyoto, Japan) was used for air-abrasion. An unfilled acrylic resin material initiated with tri- $n$ butylborane derivative (TBB) was employed as the luting material. The details of the materials used in the experiment are summarized in Table 1.

A total of 66 paired disk specimens $(8$ and $10 \mathrm{~mm}$ in diameter; $2.5 \mathrm{~mm}$ in thickness) were prepared from the two alloys, respectively. The $\mathrm{Ag}-\mathrm{Pd}-\mathrm{Cu}-\mathrm{Au}$ alloy was cast in a cristobalite investment material (Cristoquick 20, GC Corp.) using a high-frequency argon-arc casting machine (Argoncaster, Shofu, Inc.), whereas the Ti-6Al-7Nb alloy was cast in a magnesia-based investment material (Selevest $\mathrm{CB}$, Selec, Osaka, Japan) using a spin-cast centrifugal apparatus (Ticast Super R, Selec). All disks were sanded with 800-grit silicon-carbide abrasive paper.

Sixty-six disk pairs were divided into three sets of 22 disk pairs each. Of these, the first set (22 pairs for each alloy) was not air-abraded with alumina, and considered as the control group. The second set (22 pairs for each alloy) was air-abraded with alumina by means of an air-borne particle abrader (Jet Blast II, J. Morita Corp., Suita, Japan) for $10 \mathrm{~s}$ with $0.1 \mathrm{MPa}$ air-pressure. The remaining set was also air-abraded with $0.6 \mathrm{MPa}$ air-pressure. The distance of the orifice from the disk surface was $10 \mathrm{~mm}$. After surface preparation, a piece of tape with a circular hole, $5 \mathrm{~mm}$ in diameter, was positioned on each 10-mm disk specimen to define the bond area. The identically treated disk pairs were bonded together with the TBB-initiated non-adhesive resin using the brush-dip technique. Twenty-two specimens were prepared for each surface preparation group. Thirty minutes after preparation, the specimens were immersed in $37^{\circ} \mathrm{C}$ water for $24 \mathrm{~h}$ before testing for bond strength. One-half of the specimens (11 specimens; two alloys; three surfaces) were subsequently thermocycled in water between $5^{\circ} \mathrm{C}$ and $55^{\circ} \mathrm{C}$ for 10,000 cycles with 1-minute dwell time per bath (Thermal Shock Tester TTS-1 LM, Thomas Kagaku Co., Ltd., Tokyo, Japan).

Each specimen was embedded in an acrylic resin mould and seated in a shear-testing jig. Shear bond strengths were then determined with a mechanical testing machine (Type 5567, Instron Corp., Canton, MA, USA) at a crosshead speed of $0.5 \mathrm{~mm} /$ minute. Debonded surfaces were observed through an optical microscope (8x; SZX9, Olympus Corp., Tokyo, Japan), and the failure modes were classified into the following three categories: adhesive failure, cohesive failure within the luting material, and combination of adhesive and cohesive failures. Typical specimens after surface preparation, and before bonding, were observed with a scanning electron microscope (S4300, Hitachi High-Technologies Corp., Tokyo, Japan) with an accelerating voltage of $15 \mathrm{kV}$.

The bond strength results were analyzed with software for statistical analysis (SPSS version 15.0, SPSS, Inc., Chicago, IL, USA). Equality of variance of the bond strengths was primarily analyzed by Levene test and $\mathrm{F}$ test. When the Levene test and $\mathrm{F}$ test did not show equality of variances, Steel-Dwass comparison (Kyplot 4.0, KyensLab, Tokyo, Japan) was performed to evaluate the effect of alumina air-abrasion. Mann-Whitney $U$-test was used to evaluate the difference in bond strengths between pre- 
Table 2 Results of shear bond strength in $\mathrm{MPa}$

\begin{tabular}{|c|c|c|c|c|c|c|c|c|c|c|c|}
\hline \multirow[b]{2}{*}{ Alloy } & \multirow[b]{2}{*}{ Air-abrasion } & \multicolumn{2}{|c|}{0 thermocycles } & \multirow[b]{2}{*}{ SD } & \multirow[b]{2}{*}{ Category* } & \multicolumn{3}{|c|}{10,000 thermocycles } & \multirow[b]{2}{*}{ PTF } & \multirow[b]{2}{*}{ Category* } & \multirow{2}{*}{$\begin{array}{l}\text { Reduction } \\
\text { from } 0 \text { to } 10,000^{* *}\end{array}$} \\
\hline & & Median & Mean & & & Median & Mean & SD & & & \\
\hline $\mathrm{Ag}-\mathrm{Pd}-\mathrm{Cu}-\mathrm{Au}$ & None & 18.7 & 17.8 & 2.8 & a & 3.2 & 3.6 & 1.3 & 0 & $\mathrm{c}$ & Significant \\
\hline $\mathrm{Ag}-\mathrm{Pd}-\mathrm{Cu}-\mathrm{Au}$ & $0.1 \mathrm{MPa}$ & 36.4 & 36.2 & 2.1 & $\mathrm{~b}$ & 15.3 & 15.9 & 1.7 & 0 & $d$ & Significant \\
\hline $\mathrm{Ag}-\mathrm{Pd}-\mathrm{Cu}-\mathrm{Au}$ & $0.6 \mathrm{MPa}$ & 37.1 & 37.1 & 1.4 & $\mathrm{~b}$ & 22.4 & 21.7 & 1.5 & 0 & $\mathrm{e}$ & Significant \\
\hline Ti-6Al-7Nb & None & 12.3 & 11.9 & 1.6 & $f$ & 0.0 & 0.1 & 0.1 & 5 & $\mathrm{~h}$ & Significant \\
\hline Ti-6Al-7Nb & $0.1 \mathrm{MPa}$ & 35.0 & 34.7 & 2.1 & $\mathrm{~g}$ & 10.4 & 10.3 & 2.2 & 0 & $\mathrm{i}$ & Significant \\
\hline Ti-6Al-7Nb & $0.6 \mathrm{MPa}$ & 34.5 & 34.5 & 1.9 & $\mathrm{~g}$ & 17.5 & 17.9 & 1.1 & 0 & $\mathrm{j}$ & Significant \\
\hline
\end{tabular}

$n=11$; SD, Standard deviation; PTF, Number of pre-testing failures; *Identical letters indicate that the values are not significantly different (Steel-Dwass comparison; $P>0.05$ ). **Singificant difference between pre- and post-thermocycling bond strengths was found (Mann-Whitney $U$-test; $P<0.05$ ).

Table 3 Failure modes after shear bond testing

\begin{tabular}{|c|c|c|c|c|c|c|c|}
\hline \multirow[b]{2}{*}{ Alloy } & \multirow[b]{2}{*}{ Air abrasion } & \multicolumn{3}{|c|}{0 thermocycle } & \multicolumn{3}{|c|}{10,000 thermocycles } \\
\hline & & A & $\mathrm{AC}$ & $\mathrm{C}$ & A & $\mathrm{AC}$ & $\mathrm{C}$ \\
\hline $\mathrm{Ag}-\mathrm{Pd}-\mathrm{Cu}-\mathrm{Au}$ & None & 11 & 0 & 0 & 11 & 0 & 0 \\
\hline $\mathrm{Ag}-\mathrm{Pd}-\mathrm{Cu}-\mathrm{Au}$ & $0.1 \mathrm{MPa}$ & 1 & 10 & 0 & 0 & 11 & 0 \\
\hline $\mathrm{Ag}-\mathrm{Pd}-\mathrm{Cu}-\mathrm{Au}$ & $0.6 \mathrm{MPa}$ & 2 & 9 & 0 & 1 & 10 & 0 \\
\hline Ti-6Al-7Nb & None & 11 & 0 & 0 & 11 & 0 & 0 \\
\hline Ti-6Al-7Nb & $0.1 \mathrm{MPa}$ & 1 & 10 & 0 & 5 & 6 & 0 \\
\hline Ti-6Al-7Nb & $0.6 \mathrm{MPa}$ & 3 & 8 & 0 & 1 & 10 & 0 \\
\hline
\end{tabular}

A, Adhesive failure at the resin-alloy interface; $\mathrm{C}$, Cohesive failure within the resin; $\mathrm{AC}$, Combination of adhesive and cohesive failures

and post-thermocycling groups, or the difference in bond strengths between the two alloys under identical surface preparation. Significance level was set at 0.05 for all analyses.

\section{Results}

Levene test and $\mathrm{F}$ test run on the bond strength results revealed that several groups did not show equality of variance. Steel-Dwass test was therefore applied to evaluate the influence of alumina air-abrasion on bond strength. In addition, Mann-Whitney $U$-test was used for comparison of bond strengths between two different conditions.

Table 2 shows the results of shear bond testing and statistically categorized groupings. Bond strength varied from a maximum of $37.1 \mathrm{MPa}$ to a minimum of $3.6 \mathrm{MPa}$ for the Ag-Pd-Cu-Au alloy. Bond strength to Ti-6Al-7Nb alloy ranged from 34.7 MPa to 0.1 MPa. Unabraded specimens showed lower bond strength (categories a, f, c, and $h$ ) than the air-abraded specimens for both alloys. Among the three abrasion conditions, the specimens abraded with 0.6 MPa pressure recorded the greatest postthermocycling bond strength (21.7 MPa for the Ag-Pd-Au$\mathrm{Cu}$ alloy and 17.9 MPa for the Ti-6Al-7Nb alloy), and unabraded specimens showed the lowest strength (3.6 $\mathrm{MPa}$ for the Ag-Pd-Au-Cu alloy and 0.1 MPa for the Ti$6 \mathrm{Al}-7 \mathrm{Nb}$ alloy). Post-thermocycling bond strength to the Ag-Pd-Cu-Au alloy was significantly higher than that to the Ti-6Al-7Nb alloy under an identical air-abrading condition (3.6>0.1, 15.9>10.3, and 21.7>17.9). Bond strength of all six groups was reduced by thermocycling.

Table 3 shows the mode of failures after shear bond testing. All of the unabraded specimens showed adhesive 
failure, whereas many alumina-blasted specimens showed a combination of adhesive and cohesive failures. Complete cohesive failure was not observed in any of the specimens in the current study.

Figure 1 shows the ground surfaces of two alloys. Scratches generated by the abrasive paper could be seen in both specimens. Figures 2 and 3 show the alloy surfaces after air-abrasion. The surfaces of the specimens became rougher in accordance with air-pressure. The $\mathrm{Ag}-\mathrm{Pd}-\mathrm{Cu}-$ $\mathrm{Au}$ alloy surface abraded with 0.6 MPa pressure was rougher than the Ti-6Al-7Nb alloy surface abraded with the same pressure.
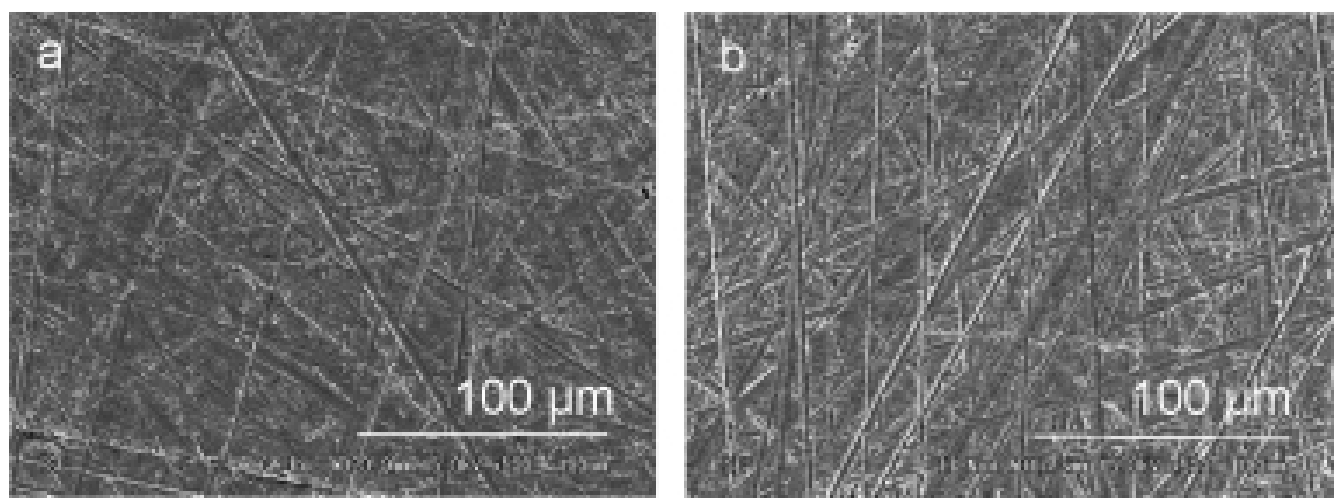

Fig. 1 Scanning electron micrographs of (a) Ag-Pd-Cu-Au alloy and (b) Ti-6Al-7Nb alloy ground with \#800 SiC abrasive paper (original magnification, $\times 500$ ).
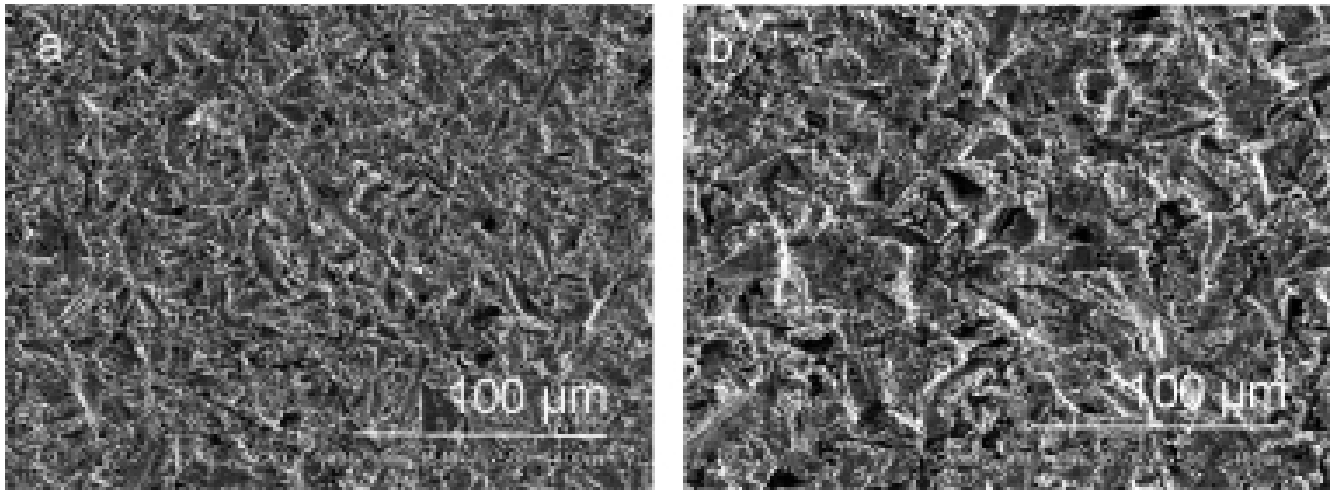

Fig. 2 Scanning electron micrographs of alumina-abraded $\mathrm{Ag}-\mathrm{Pd}-\mathrm{Cu}-\mathrm{Au}$ alloy with $0.1 \mathrm{MPa}$ (a) and 0.6 MPa (b) air-pressures (original magnification, $\times 500$ ).
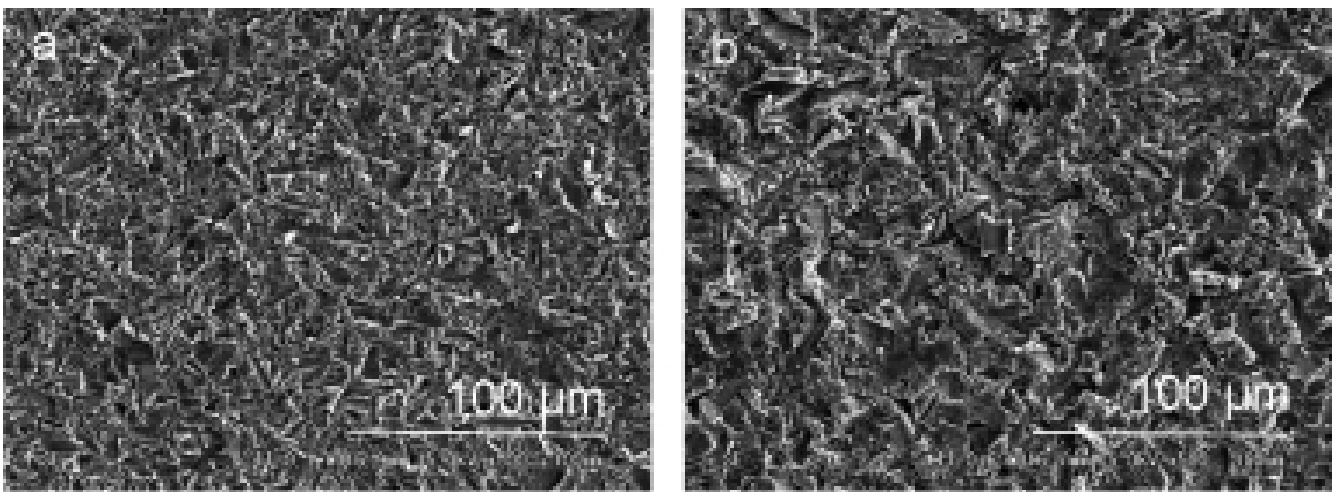

Fig. 3 Scanning electron micrographs of alumina-abraded Ti-6Al-7Nb alloy with $0.1 \mathrm{MPa}$ (a) and $0.6 \mathrm{MPa}(\mathrm{b})$ air-pressures (original magnification, $\times 500$ ). 


\section{Discussion}

This study compared the influence of different aluminaabrasion pressures on bonding between an acrylic resin and two casting alloys. The authors did not use adhesive functional monomers in order to evaluate the single effect of alumina air-abrasion.

As shown in Table 1, alumina air-abrasion effectively enhanced bond strength of the resin material (categories $\mathrm{a}$ and $\mathrm{b}$; $\mathrm{f}$ and $\mathrm{g}$ ). The difference between the two airpressure conditions, however, was not significant (categories b or g) at the pre-thermocycling state. This is probably due to cohesion of resin material to the roughened alloys before penetration of water into the adhesive interface. Also, the result was slightly different from that of a previous paper reporting effects of alumina air-abrasion on bond strength to Ti-6Al-7Nb alloy (16). The authors speculate that the disparity in results could be attributed to the differences in the bonded material, the distance between the surface to be abraded and aperture of the air-borne particle abrader (10 $\mathrm{mm}$ in this paper and $20 \mathrm{~mm}$ in reference 16), and the abrasion time period ( $10 \mathrm{~s}$ in this paper and $15 \mathrm{~s}$ in reference 16).

After thermocycling, significant differences in bond strength were found among the three surface conditions. Specifically, specimens abraded with $0.6 \mathrm{MPa}$ pressure recorded the highest bond strength (categories e and $\mathrm{j}$ ), while unabraded specimens resulted in the lowest bond strength (categories $\mathrm{c}$ and $\mathrm{h}$ ). The results can be explained by the difference in surface roughness of the specimens shown in Figs. 1 - 3. The rougher surface of the Ag-Pd$\mathrm{Cu}-\mathrm{Au}$ alloy as compared with the Ti-6Al-7Nb alloy may be due to the difference in hardness between the two alloys (146 VHN for Ag-Pd-Cu-Au alloy and $320 \mathrm{VHN}$ for Ti$6 \mathrm{Al}-7 \mathrm{Nb}$ alloy). Although the rougher surface might be more retentive than the smoother surface for the nonadhesive acrylic resin, clinicians should note that mechanical properties of $\mathrm{Ag}-\mathrm{Pd}-\mathrm{Cu}-\mathrm{Au}$ alloy are inferior to those of Ti-6Al-7Nb alloy (17), even if Ag-Pd-Cu-Au alloy has been age-hardened.

Statistical analyses also revealed that post-thermocycling bond strength of the TBB resin to the Ag-Pd-Cu-Au alloy was significantly higher than that to the Ti-6Al-7Nb alloy for all three surfaces $(c>h, d>i$, and $e>j)$. Since the resin material did not contain any functional monomer in the composition, this could be explained by the difference in surface texture of the alloys. Among the three surface preparations, $\mathrm{Ag}-\mathrm{Pd}-\mathrm{Cu}-\mathrm{Au}$ alloy appeared to be rougher than Ti-6Al-7Nb alloy when the surface was abraded with $0.6 \mathrm{MPa}$ air-pressure (Figs. $2 \mathrm{~b}$ and $3 \mathrm{~b}$ ). The difference in surface roughness between the two alloys is consistent with the difference in post-thermocycling bond strength reported here.

Overall, shear bond testing results demonstrated the effectiveness of alumina air-abrasion for bonding to both the casting alloys. The question of the bonding durability of mechano-chemical retention systems remains, and needs to be evaluated. On the basis of the current study, the application of alumina air-abrasion with $0.6 \mathrm{MPa}$ pressure is recommended for bonding the TBB-initiated acrylic resin to the two casting alloys.

\section{Acknowledgments}

This work was supported in part by Grant-in-Aid for Scientific Research C 20592302 (2008) from the Japan Society for the Promotion of Science (JSPS), Special Research Grant for the Development of Distinctive Education from the Promotion and Mutual Aid Corporation for Private School of Japan (2008), a grant from Dental Research Center A (2008), and Sato Fund (2008), Nihon University School of Dentistry.

\section{References}

1. Hansson O, Bergström B (1996) A longitudinal study of resin-bonded prostheses. J Prosthet Dent $76,132-139$.

2. Pröbster B, Henrich GM (1997) 11-year follow-up study of resin-bonded fixed partial dentures. Int J Prosthodont 10, 259-268.

3. Monya Y, Matsumura H, Atsuta M (1998) A twostage resin-bonded fixed partial denture seated in conjunction with post-extraction healing of the alveolar socket: a clinical report. J Prosthet Dent 80, 4-8.

4. Matsumura H, Yoneyama T, Shimoe S (2002) Veneering technique for a Ti-6Al-7Nb framework used in a resin-bonded fixed partial denture with a highly filled indirect composite. J Prosthet Dent 88, 636-639.

5. Hikage S, Hirose Y, Sawada N, Endo K, Ohno H (2003) Clinical longevity of resin-bonded bridges bonded using a vinyl-thiol primer. J Oral Rehabil 30, 1022-1029.

6. Shimizu H, Takahashi Y (2004) Retainer design for posterior resin-bonded fixed partial dentures: a technical report. Quintessence Int 35, 653-654.

7. Atsuta M, Matsumura H, Tanaka T (1992) Bonding fixed prosthodontic composite resin and precious metal alloys with the use of a vinyl-thiol primer and an adhesive opaque resin. J Prosthet Dent 67, 296300 .

8. Matsumura H, Kamada K, Tanoue N, Atsuta M (2000) Effect of thione primers on bonding of noble 
metal alloys with an adhesive resin. J Dent 28, 287293.

9. Yanagida H, Matsumura H, Atsuta M (2001) Bonding of prosthetic composite material to Ti$6 \mathrm{Al}-7 \mathrm{Nb}$ alloy with eight metal conditioners and a surface modification technique. Am J Dent 14, 291294.

10. Ishii T, Koizumi H, Yoneyama T, Tanoue N, Ishikawa Y, Matsumura H (2008) Comparative evaluation of thione and phosphate monomers on bonding gold alloy and Ti-6Al-7Nb alloy with tri-n-butylborane initiated resin. Dent Mater J 27, 56-60.

11. Mukai M, Fukui H, Hasegawa J (1995) Relationship between sandblasting and composite resin-alloy bond strength by a silica coating. J Prosthet Dent 74, 151-155.

12. Peutzfeldt A, Asmussen E (1996) Distortion of alloy by sandblasting. Am J Dent 9, 65-66.

13. Papadopoulos T, Tsetsekou A, Eliades G (1999) Effect of alumina oxide sandblasting on cast commercially pure titanium surfaces. Eur $\mathbf{J}$ Prosthodont Restor Dent 7, 15-21.

14. Watanabe I, Kurtz KS, Kabcenell JL, Okabe T (1999) Effect of sandblasting and silicoating on bond strength of polymer-glass composite to cast titanium. J Prosthet Dent 82, 462-467.

15. Taga Y, Kawai K, Nokubi T (2001) New method for divesting cobalt-chromium alloy castings: sandblasting with a mixed abrasive powder. J Prosthet Dent 85, 357-362.

16. Sugawara H, Yanagida H, Tanoue N, Koishi Y, Nagano K, Atsuta M, Matsumura H (2004) Effect of alumina abrasion for bonding between Ti-6Al$7 \mathrm{Nb}$ alloy and an indirect composite. Int Chin $\mathrm{J}$ Dent 4, 8-14.

17. Kobayashi E, Wang TJ, Doi H, Yoneyama T, Hamanaka H (1998) Mechanical properties and corrosion resistance of Ti-6Al-7Nb alloy dental castings. J Mater Sci Mater Med 9, 567-574. 